\title{
Metabolic profiling and method validation of marker compounds from Saposhnikoviae Radix and Peucedani Japonici Radix
}

\author{
Bo-Ram Choi ${ }^{1} \cdot$ Dahye Yoon $^{1} \cdot$ Geum-Soog Kim $^{1} \cdot$ Kyung-Sook Han $^{1}$. \\ Doo Jin Choi ${ }^{1}$ - Young-Seob Lee ${ }^{1}$. Do Yoon Hyun ${ }^{2}$. Dae Young Lee ${ }^{1}$
}

\section{방풍, 식방풍의 대사체 프로파일링을 통한 지표성분 선정 및 분석법검증}

\author{
최보람 ${ }^{1} \cdot$ 윤다혜 $^{1} \cdot$ 김금숙 $^{1} \cdot$ 한경숙 $^{1} \cdot$ 최두진 $^{1} \cdot$ 이영섭 $^{1} \cdot$ 현도윤 $^{2} \cdot$ 이대영 $^{1}$
}

Received: 25 October 2020 / Accepted: 1 November 2020 / Published Online: 31 December 2020

(C) The Korean Society for Applied Biological Chemistry 2020

\begin{abstract}
Saposhnikoviae Radix (SR) and Peucedani Japonici Radix (PR) have been used as the main traditional herbal medicines in Korea, China and Japan. In this study, ultraperformance liquid chromatography coupled to quadrupole time of flight mass spectrometry (UPLC-QTOF/MS)-based metabolomics was applied to evaluate the quality of SR and PR using the marker compounds. In the S-plot of SR and PR, 5-O-methylvisammioside and peucedanol were selected as a marker compound for SR and PR, respectively. Also, an UPLC method was established and well validated for marker compounds of SR and PR. These results suggested that the established analysis method could be used one of the good methods for the classification and quality assessment of SR and PR.
\end{abstract}

Keywords Metabolic profiling - Method validation 5-Omethylvisammioside - Peucedani Japonici Radix · Peucedanol · Saposhnikoviae Radix

Dae Young Lee $(\bowtie)$

E-mail:dylee0809@gmail.com

${ }^{1}$ Department of Herbal Crop Research, National Institute of Horticultural and Herbal Science, RDA, Eumseong 27709, Republic of Korea

${ }^{2}$ National Agrobiodiversity Center, National Institute of Agricultural Sciences, RDA, Jeonju 54874, Republic of Korea

This is an Open Access article distributed under the terms of the Creative Commons Attribution Non-Commercial License (http://creativecommons. org/licenses/by-nc/3.0/) which permits unrestricted non-commercial use, distribution, and reproduction in any medium, provided the original work is properly cited.
서 론

미나리과(Umbelliferae)에 속하는 방풍(Saposhnikovia divaricate (Turcz.) Schischk)은 진방풍, 산방풍, 병풍나물 등으로 불린다. 시베리아, 중국 몽고 등에 분포하며, 뿌리는 한국 및 중국 등에 서 류머티즘, 두통, 어지럼증, 관절통 등의 치료에 사용된다고 보고되어 있다[1,2]. 최근 연구된 방풍의 생리활성으로는 알레르 기가 유도된 마우스에서 알레르기 반응 억제[3], 멜라닌 생성 및 엘라스타제 활성 억제[4], 퇴행성 관절염 억제[5], 항염증 효 과[6] 등이 보고되어 있다.

방풍은 chromone 계열 화합물, coumarin 계열 화합물, alkane 계열 화합물 및 다당류 등의 다양한 종류의 기능성 화합물을 포함하고 있다고 알려져 있다[7]. Chromone 계열 화합물은 flavonoids에서 유래한 헤테로(hetero) 고리의 방항족 화합물이며 방풍의 대표적인 chromone 화합물로는 prim- $O$-glucosylcimifugin, 4-O- $\beta$-D-glucosyl-5-O-methylvisamminol, cimifugin, Sec- $O$-glucosylhamaudol, 5-O-methylvisamminol 등이 있다[8]. 이러한 chromone 계열의 화합물들은 앞에서 언급한 진통, 항염증 등의 생리 활 성을 나타내는 방풍의 대표적인 활성성분으로 알려져 있다[9].

식방풍은 방풍과 같은 미나리과(Umbelliferae)에 속하는 갯기 름나물(Peucedanum japonicum Thunb.)의 뿌리를 일컫는다. 갯 기름나물은 우리나라를 포함한 동아시아 지역의 해안지대에 주 로 분포하며, 한국에서는 잎과 줄기를 방풍나물이라고 부르며 식용으로 이용한다[10,11]. 한방에서는 중풍, 감기, 신경통 등의 치료에 사용되며, 방풍의 대용으로 이용하여 왔다[12,13]. 최근 의 연구에서는 식방풍 추출물의 비만 억제[14], 항산화 작용[15] 및 혈관성 치매 예방[16] 등의 생리활성이 알려져 있다.

식방풍의 주요성분으로는 coumarin계열 지용성 성분인 bergapten, psolalen, praeruptorin A, xanthotoxin, nodakenetin, 및 peujaponiside 등이 보고되어 있으며, chromone계열 화합물 
은 방풍과는 달리 nodakenetin의 배당체인 nodakenin, decuroside $\mathrm{I}-\mathrm{V}$ 및 peucedanol 배당체가 주요성분으로 보고되어 있다 $[17,18]$.

'대한민국약전'에서는 Saposhnikovia divaricate (Turcz.) Schischk의 뿌리 및 뿌리줄기를 방풍의 기원식물로 인정하고 있 지만, 유통되는 생약에는 식방풍을 포함하여 해방풍, 산방풍 등 이 방풍으로 분류되어 사용되고 있다. 이들 중 갯기름나물의 뿌 리인 식방풍은 방풍과 동일한 미나리과 식물로서 방풍 대용으 로 사용하지만, 속과 종이 방풍과는 다른 식물이다. 또한, 이들 의 외형적 특징으로 구분하기에는 차이가 충분하지 않으며, 절 편 또는 가루형태로 유통되었을 시에는 더욱더 판별하기가 어 려운 실정이다. 최근의 생약 연구에서는 대사체학을 이용한 판 별 연구들이 증가하고 있는데 방풍, 식방풍과 마찬가지로 혼용 되어 사용되는 백수오, 이엽우피소의 판별[19] 뿐만 아니라, 원 산지 판별[20] 등의 다양한 분야에서 대사체학이 응용되고 있 으며 그 중요성은 점점 더 커지고 있다.

따라서, 본 연구에서는 혼용되어 사용되고 있는 방풍과 식방 풍을 구별하기 위해, 미량의 물질까지도 분석이 가능한 질량분 석기가 결합된 고속액체크로마토그래피 UPLC-Q-TOF/MS를 이 용하여 대사체 프로파일링 및 다변량 통계분석을 통해 각각의 특이적인 대사체를 선정하였으며, 상업적으로 상용되는 UPLC 를 이용한 신속한 분석법을 확립하고자 하였다.

\section{재료 및 방법}

\section{실험재료}

본 연구에서는 시중에서 건조된 상태로 유통되고 있는 국내산 방풍 및 식방풍을 각각 10 종을 구입하였으며, 국립원예특작과 학원 약용작물과 박춘근 박사가 동정 및 기원을 확인하였다. 표 본 시료(NIHHS19-B1, B2)는 국립원예특작과학원 인삼특작부에 보관되어 있다. 유통되는 시료를 확인하고자 식약처에서 분양받 은 방풍(SADI2008) 및 식방풍(PEJA2012)을 분쇄하여 검증 시 료로 사용하였다.

\section{시약 및 기기}

방풍과 식방풍의 대사체 프로파일링 분석은 UPLC-QTOF/MS를 이용하였다. UPLC 분석은 Waters ACQUITY I-Class UPLC (Waters Co., Milford, MA, USA)를 사용하였으며, TOF MS는 Waters Xevo G2-S QTOF MS (Waters Co.)를 사용하였다. 방 풍과 식방풍의 지표성분 분석법 검증에 사용된 UPLC는 Waters UPLC I-Class (Waters Co.)를 사용하였다. 지표성분으로 사용된 표준물질, 5-O-methylvisammioside (순도 99.6\%)와 peucedanol (순도 98\%)은 Chem Faces (Hubei, China)에서 구입하여 사용 하였다. 분석을 위한 증류수, Methanol $(\mathrm{MeOH})$ 및 Acetonitrile 은 HPLC급 (Fisher Scientific Inc., Hampton, NH, USA)을 사용하였으며(순도 $99.9 \%$ ), 그 외 사용된 시약 및 용매는 모두 일급 이상으로 사용하였다.

\section{시료추출}

건조 및 조분쇄 된 방풍, 식방풍 및 표준 생약시료를 볼밀 (Retsch MM400 mixer mill, Haan, Germany)을 이용하여 미
세분말로 분쇄하였다. 최적 추출 용매 조건을 위해 50,70 , $100 \% \mathrm{MeOH}$ 를 이용하여 시료를 추출하고 물질들의 패턴을 비 교하여 $50 \% \mathrm{MeOH}$ 의 조건을 최종 용매 조건으로 선정하였다. 시료 $100 \mathrm{mg}$ 씩 $2 \mathrm{~mL}$ 튜브에 취하고 $50 \% \mathrm{MeOH} 1 \mathrm{~mL}$ 을 더 한 후 초음파추출기를 이용하여 상온조건에서 60 분 동안 추출 하였다. 이후 원심분리기를 이용하여 상등을 분리한 다음 $(13,500$ $\mathrm{rpm}, 5 \mathrm{~min}$ ) 상등액을 $0.2 \mu \mathrm{m}$ 필터를 이용하여 여과한 후, 20 배 희석하여 분석에 사용하였다.

\section{대사체 프로파일링}

방풍과 식방풍의 대사체 프로파일링 분석은 UPLC-QTOF/MS를 이용하였다. UPLC와 Q-TOF/MS는 각각 Waters ACQUITY IClass UPLC에 Waters Xevo G2-S Q-TOF/MS가 부착된 장비 를 사용하였다. UPLC 분석에 사용된 컬럼은 ACQUITY BEH C18 column $(2.1 \mathrm{~mm} \times 100 \mathrm{~mm}, 1.7 \mu \mathrm{m})$ 의 역상 컬럼을 사용하 였으며 분석 시에 컬럼 오븐 내부의 온도는 $30^{\circ} \mathrm{C}$ 를 유지하였 다. 증류수 $(\mathrm{A})$ 와 Acetonitrile $(\mathrm{B})$ 을 이동상으로 사용하였으며 기 울기 조건은 $5 \%$ 의 $\mathrm{B}$ 를 10 분 동안 $20 \%$ 로 증가시키고, 이어서 7 분동안 $70 \%$ 로 증가시키고, 이후 5 분 동안 $\mathrm{B}$ 를 $100 \%$ 까지 증 가시킨 후 4 분간 다시 $5 \%$ 로 감소시켜 2 분간 유지하였다. 이동 상의 유속은 $0.4 \mathrm{~mL} / \mathrm{min}$ 을 유지하고 주입량은 $2 \mu \mathrm{L}$ 이었다. Q$\mathrm{TOF} / \mathrm{MS}$ 분석은 ESI 소스의 Negative Mode조건하에서 실험하 였으며 Capillary 전압과 Cone 전압은 각각 $3.5 \mathrm{kV}, 40 \mathrm{~V}$ 로 분 석하였다. Ion source와 Desolvation 온도는 각각 $120,550{ }^{\circ} \mathrm{C}$ 로 설정하였고, Desolvation 및 Cone 가스의 유속은 각각 800, $30 \mathrm{~L} / \mathrm{h}$ 로 유지하였다. 대사체 분석을 위한 질량값 Scan 범위는 $100-2,000 \mathrm{~m} / \mathrm{z}$ 이며, 질량값의 정확성을 위해 Leucine-enkephalin $[\mathrm{m} / \mathrm{z} 554.262$ (ESI-)]을 내부 표준용액으로 사용하였다. 모든 $\mathrm{MS}$ 데이터는 $\mathrm{MS}^{\mathrm{E}}$ mode로 분석하였으며 Masslynx (Waters $\mathrm{Co}$.)를 이용하여 수집하였다.

\section{데이터처리 및 통계처리}

수집된 데이터의 peak acquisition과 대사체의 alignment를 위해 Progenesis QI software (Waters Co.)를 사용하였다. TOF-MS 를 통해 수집된 모든 데이터는 chromatographic peak alignment, peak picking, normalization, compound identification의 과정을 거쳐, ion intensity, $\mathrm{m} / \mathrm{z}$ 와 retention time을 포함하는 데이터로 처리되었다. 처리된 데이터의 다변량 통계 분석을 위해 SIMCAP software (v15.0, Umetrics AB, Umea, Sweden)를 이용하였 다. 통계 분석은 PCA, PLS-DA, OPLS-DA 순으로 진행하였으 며, score plot 과 S-plot을 구하였다. 이때 얻어지는 $\mathrm{R}^{2}, \mathrm{Q}^{2}$ 값 은 각각 통계모델에서의 적합도(goodness of fit)와 통계적인 예 측도(goodness of prediction)를 나타낸다[21]. 데이터 통계처리 전 pareto scale로 평균 중심화(mean-centering) 하였다.

\section{분석법 검중}

$\mathrm{UPLC}$ 를 이용한 방풍과 식방풍의 분석법 검증은 PDA detector 가 결합된 Waters UPLC I-Class (Waters Co.)를 이용하였으며 ACQUITY BEH C18 column $(2.1 \mathrm{~mm} \times 100 \mathrm{~mm}, 1.7 \mu \mathrm{m})$ 을 사용하였다. 증류수와 Acetonitrile (B)을 이동상으로 하였으며 유속은 $0.4 \mathrm{~mL} / \mathrm{min}$ 을 유지하였다. 기울기 조건은 $5 \%$ 의 $\mathrm{B}$ 를 6 분 동안 $12 \%$ 로 증가시키고 2 분 동안 $20 \%$ 로 증가시켰다. 이후 
$25 \%$ 로 2 분 동안 증가시키고 7 분 동안 $70 \%$ 로 증가시킨 후, 5 분 동안 $100 \%$ 로 증가시켰다. 4 분 동안 초기 조건인 $5 \%$ 로 감 소시킨 다음 2 분간 유지하였다. UV 검출기의 $210 \mathrm{~nm}$ 파장에서 흡광도를 측정하였으며 시료 주입량은 $2 \mu \mathrm{L}$ 이었다.

Marker compound인 5-O-methylvisammioside와 peucedaonl 을 methanol에 녹여 표준용액을 제조하여 표준정량곡선 작성에 이용하였다. 지표물질 분석법 검증을 위해 특이성(specificity), 직선성(linearity), 검출한계(limit of detection), 정량한계(limit of quantitation), 정확성(accuracy) 및 정밀성(precision)으로 분석법 의 유효성을 검증하고자 하였다. 2 종의 marker compound에 대 하여 3 종의 농도조건으로 5 일동안 반복 분석하는 inter-day, 연 속으로 5 회 분석하는 intra-day 분석으로 정밀성(precision) 및 정확성(accuracy)을 구하여 분석법의 재현성(reproducibility)을 확 인하였다. 각 성분에 대한 $\mathrm{LOD}, \mathrm{LOQ}$ 는 각 성분에 대한 표준 정량곡선의 signal-to-noise 값이 각각 3,10 일때의 농도로 구하 였다.

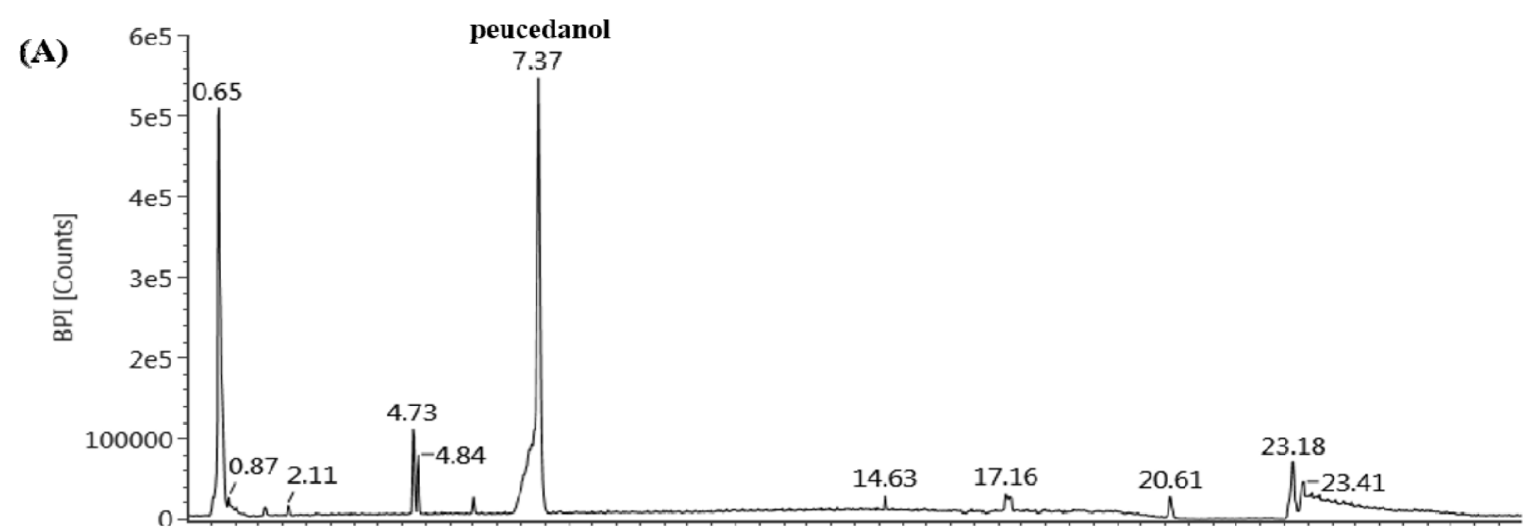

(B)

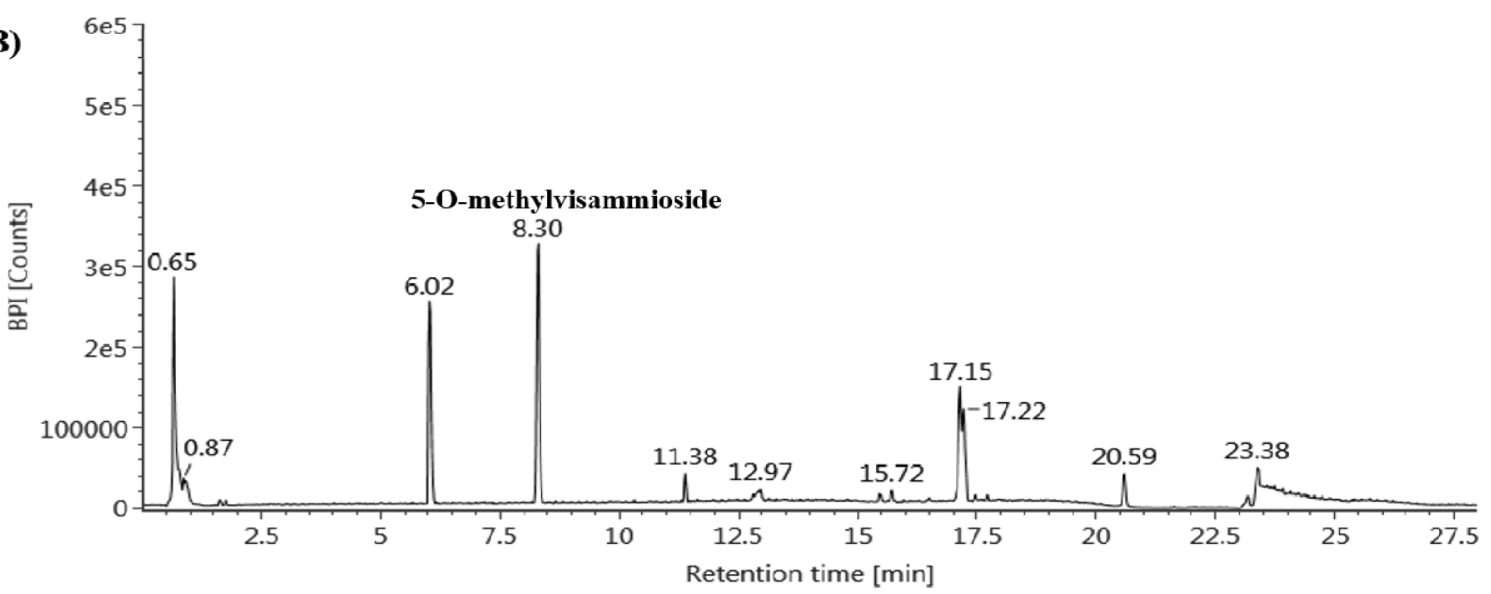

(C)

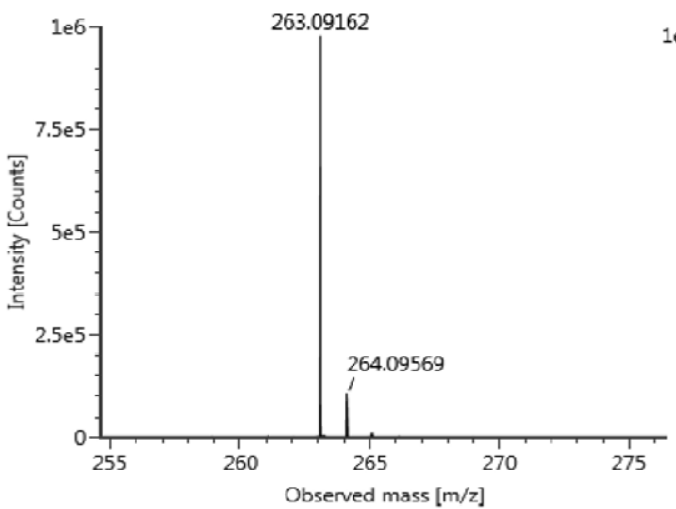

(D)

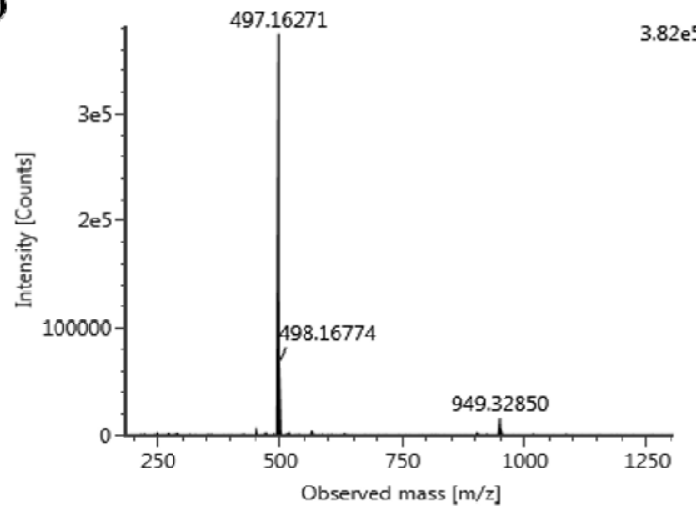

Fig. 1 The base peak intensity (BPI) chromatogram of (A) Peucedani Japonici Radix and (B) Saposhnikoviae Radix and MS spectrum of (C) peucedanol and (D) 5-O-methylvisammioside 


\section{결과 및 고찰}

최근, 대사체분석 및 미지의 물질을 정확한 질량값을 찾고자 할 때 사용되는 UPLC-QTOF/MS를 이용하여 방풍, 식방풍 및 표 준생약 시료를 분석하였다. $50 \% \mathrm{MeOH}$ 을 이용하여 추출한 시 료를 Negative ion mode에서 분석한 결과, 방풍과 식방풍의 질 량분석 크로마토그램은 뚜렷하게 구분되는 것을 확인할 수 있 었다(Fig. 1). 방풍의 크로마토그램에서 나타나는 6분대, 8.3분 대의 피크가 식방풍의 크로마토그램에서는 각각 아주 작은 피 크를 나타내거나, 피크가 검출되지 않았다. 반면에 식방풍의 크 로마토그램에서 확인된 7.3분대의 피크는 방풍의 BPI 크로마토 그램에서는 나타나지 않았다. 방풍과 식방풍을 구별하는 대사체 들을 확인하기 위해서 UPLC-QTOF-MS 분석을 진행하여 얻은 방풍 $(n=10)$, 식방풍 $(n=10)$ 데이터에 대하여 다변량 통계분석을 진행하였다(Fig. 2). 방풍과 식방풍 사이의 군집 경향을 확인하 기 위해 PCA score plot을 구하였으며 $\left(\mathrm{R}^{2} \mathrm{X}=0.724, \mathrm{R}^{2} \mathrm{Y}=0.0681\right.$, $\left.\mathrm{Q}^{2}=0.778\right)$, 방풍과 식방풍의 개별 샘플들이 각각 중첩되지 않고
잘 구분되는 것을 확인할 수 있었다. PLS-DA score plot $\left(\mathrm{R}^{2} \mathrm{X}=0.723, \mathrm{R}^{2} \mathrm{Y}=0.0679, \mathrm{Q}^{2}=0.998\right)$ 도 $\mathrm{PCA}$ score plot과 동 일하게 방풍, 식방풍 개별 샘플들이 서로 중첩되지 않고 잘 구 분되었다. 방풍과 식방풍의 차이를 구분하는 세부적인 대사체를 확인하기 위해 OPLS-DA $\left(\mathrm{R}^{2} \mathrm{X}=0.716, \mathrm{R}^{2} \mathrm{Y}=0.0749, \mathrm{Q}^{2}=0.998\right)$ 를 통해 얻어진 S-plot을 구하였다.

S-plot은 score plot 에서의 대사체와 그룹 간의 공분산 (covariance)과 상관관계(correlation)를 나타내며, S-plot의 중심 축을 벗어난 성분들은 그룹을 구분 짓게 한다. S-plot에서 $\mathrm{p}$ (corr) 값의 높고 낮음은 두 집단을 구별하는 유의미한 값을 나 타낸다[22,23]. 이러한 특징으로 인해 인삼의 연근판별[24], 인 삼의 가공별 대사체 분석[25], 생육조건별 인삼의 대사체 분석 [26], 홍차의 등급 분류[27] 등 다양한 대사체 분석에 사용되고 있다. 방풍과 식방풍의 S-plot에서 각 포인트는 방풍, 식방풍의 $\mathrm{MS}$ 분석 데이터에서 RT-m/z를 나타낸다. S-plot에서 우측 상단 은 방풍에서 증가하는 성분을 나타낸다. 방풍에서 유의성을 나 타내는 6 개의 성분 중 $5-O$-methylvisammioside $(8.28 \mathrm{~min}$,
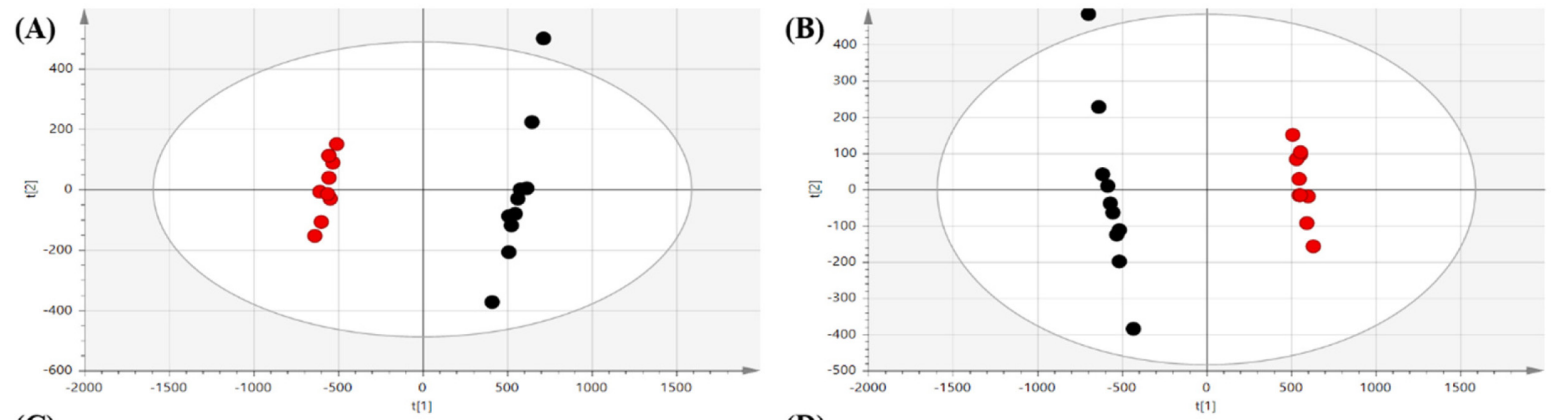

(C)

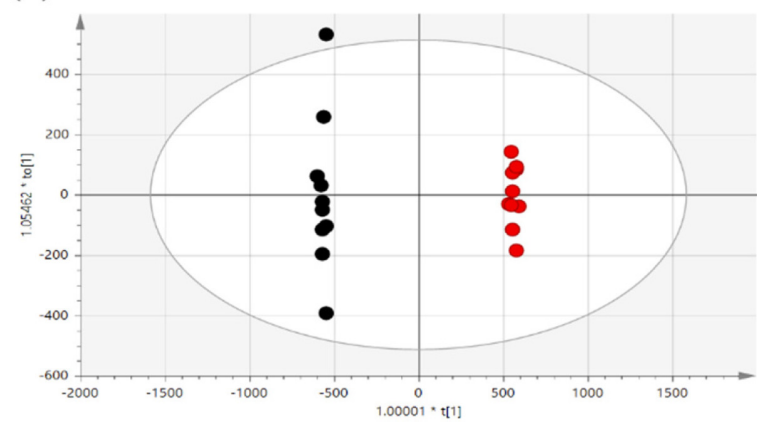

(D)

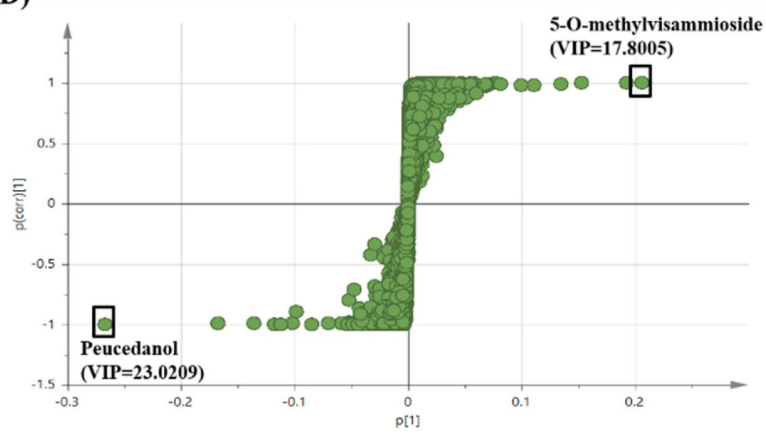

Fig. 2 The multivariate statistical analysis of Peucedani Japonici Radix and Saposhnikoviae Radix (A) PCA score plot $\left(R^{2} X=0.724, R^{2} Y=0.0681\right.$, $\left.\mathrm{Q}^{2}=0.778\right)$, (B) PLS-DA $\left(\mathrm{R}^{2} \mathrm{X}=0.723, \mathrm{R}^{2} \mathrm{Y}=0.0679, \mathrm{Q}^{2}=0.998\right)$, (C) OPLS-DA $\left(\mathrm{R}^{2} \mathrm{X}=0.716, \mathrm{R}^{2} \mathrm{Y}=0.0749, \mathrm{Q}^{2}=0.998\right)$ and (D) OPLS-DA loading S-plot $\left(\mathrm{R}^{2} \mathrm{X}=0.716\right)$

(A)

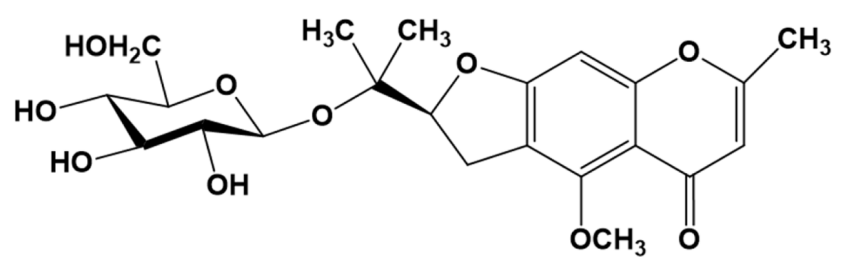

(B)<smiles>COc1cc2oc(=O)ccc2cc1C[C@@H](O)C(C)(C)O</smiles>

Fig. 3 Chemical structure of marker compounds for Peucedani Japonici Radix and Saposhnikoviae Radix [5-O-methylvisammioside (A) and peucedanol (B)] 

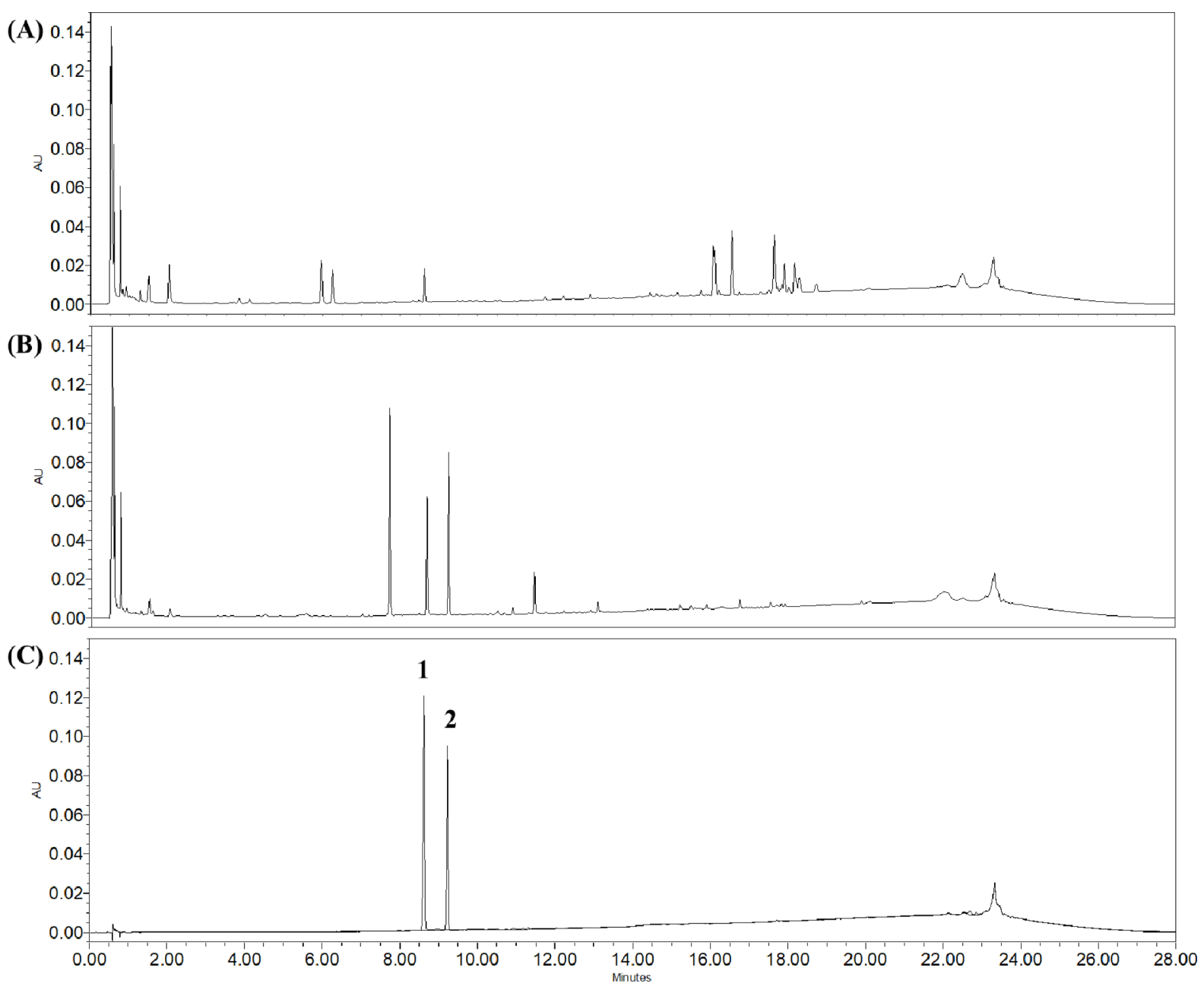

Fig. 4 UPLC analysis of (A) Peucedani Japonici Radix, (B) Saposhnikoviae Radix and (C) marker compounds [peucedanol (1) and 5-Omethylvisammioside (2)]

$452.1661 \mathrm{~m} / \mathrm{z}$ )이 가장 높은 유의성을 나타내는 것으로 확인되 었다(VIP=17.8005). 반면에 S-plot의 좌측 하단은 식방풍에서 증 가하는 성분을 나타내는데, peucedanol $(7.37 \mathrm{~min}, 263.0919 \mathrm{~m} / \mathrm{z})$ 이 가장 높은 유의성을 나타내는 것을 확인하였다(VIP=23.0209).

5-O-methylvisammioside는 방풍의 대표적인 chromone 계열 화합물 중 하나로 특히 방풍에서의 함량이 높다고 알려져 있으 며[8] 방풍의 다양한 약리적인 활성과 가장 연관 있는 화합물 로 여겨진다[28]. 또한 최근의 연구에서는 5-O-methylvisammioside 가 혈관질환과 초기 뇌 손상 예방에 강력한 면역 억제제로서의 가능성을 나타내고 있다[29].

Peucedanol은 식방풍 뿌리에 가장 많이 함유되어 있으며[30], 식방풍의 약리효과와 연관이 크다고 알려져 있다[31]. 최근의 연구에서는 peucedanol이 항산화와 butyrylcholinesterase 저해에 효과를 나타낸다고 알려져 있다[32].

위에서 언급된 다변량 통계분석 결과를 바탕으로 5-Omethylvisammioside와 peucedanol을 방풍과 식방풍의 지표성분 으로 제안할 수 있음을 확인하였으며, UPLC를 이용하여 분석 법을 검증하고자 하였다(Fig. 3). 지표성분으로 제안된 5-Omethylvisammioside 와 peucedanol을 UPLC로 정성 분석한 결
과, 방풍과 식방풍 추출물에서 상대적 함량 차이가 크게 나는 것을 확인할 수 있었다(Fig. 4).

분석법의 검증은 식품의약품안전처의 '의약품등 시험방법 밸 리데이션 가이드라인' 및 '생약(한약)제제의 성분 프로파일 설 정 가이드라인'에 따라 특이성, 직선성, 범위, 검출한계, 정량한 계, 정확성 및 정밀성에 대한 평가를 실행하였다. 5-O-methylvisammioside와 peucedanol의 회귀식은 Table 1에 나타내었으며, 각각의 상관계수 $\left(\mathrm{r}^{2}\right)$ 값은 $0.9996,0.9991$ 로 높은 직선성을 나타 내었다. 5-O-methylvisammioside와 peucedanol의 검출한계(LOD) 는 각각 0.44 및 $0.53 \mathrm{ng} / \mu \mathrm{L}$ 이었고, 정량한계(LOQ)는 0.58 및 $0.72 \mathrm{ng} / \mu \mathrm{L}$ 로 측정되었다. 또한, 지표성분 2 종에 대해서 2,5 , $10 \mathrm{ng} / \mu \mathrm{L}$ 의 3가지 농도로 일내분석(intra-day) 및 일간분석(interday)을 실시하여 정밀성(precision), 정확도(accuracy)를 구하여 UPLC 분석법의 재현성을 검증하였으며 Table 2에 나타내었다. 일내분석은 3 가지 농도를 5 회 반복하여 분석하였으며 일간분석 은 3 가지 농도를 연속 5 일 동안 반복 분석하여 재현성을 구하 고자 하였다. 정밀성은 상대표준오차 값으로 나타내었으며, 정 확도는 회수율로 나타내었다. 5-O-methylvisammioside의 일내분 석의 정밀성은 $0.72-0.89 \%$, 정확도는 $102.66-112.36 \%$ 및 일간 
Table 1 The regression data, LOD and LOQ for marker compounds for Peucedani Japonici Radix and Saposhnikoviae Radix by UPLC analysis

\begin{tabular}{|c|c|c|c|c|c|c|c|}
\hline \multirow{2}{*}{ Compounds } & \multirow{2}{*}{ Calibration curves } & \multirow{2}{*}{$\begin{array}{l}\text { Correlation coefficient } \\
\qquad\left(\mathrm{r}^{2}\right)\end{array}$} & \multirow{2}{*}{$\begin{array}{c}\text { Concentration range } \\
(n g / \mu L)\end{array}$} & \multicolumn{2}{|c|}{$\mathrm{LOD}^{1)}(\mathrm{ng} / \mu \mathrm{L})$} & \multicolumn{2}{|c|}{$\mathrm{LOD}^{2)}(\mathrm{ng} / \mu \mathrm{L})$} \\
\hline & & & & Conc. & $\mathrm{S} / \mathrm{N}$ & Conc. & $\mathrm{S} / \mathrm{N}$ \\
\hline 5-O-methylvisammioside & $y=19843 x-3995.9$ & 0.9999 & $0.024-100$ & 0.44 & 3 & 0.58 & 10 \\
\hline peucedanol & $y=29772 x-15417$ & 0.9991 & $0.024-100$ & 0.53 & 3 & 0.72 & 10 \\
\hline
\end{tabular}

${ }^{1)} \mathrm{LOD}$; Limit of detection, ${ }^{2)} \mathrm{LOQ}$; Limit of quantification

Table 2 Accuracy and precision data of marker compounds of Peucedani Japonici Radix and Saposhnikoviae Radix by UPLC analysis

\begin{tabular}{|c|c|c|c|c|c|c|c|}
\hline \multirow[b]{2}{*}{ Compounds } & \multirow{2}{*}{$\begin{array}{l}\text { Spiked conc. } \\
\quad(\mathrm{ng} / \mu \mathrm{L})\end{array}$} & \multicolumn{3}{|c|}{ Intra-day precision $(\mathrm{n}=5)$} & \multicolumn{3}{|c|}{ Inter-day precision $(\mathrm{n}=5)$} \\
\hline & & $\begin{array}{c}\text { Measured }^{1)} \\
(\mathrm{ng} / \mu \mathrm{L})\end{array}$ & $\begin{array}{c}\mathrm{RSD}^{2)} \\
(\%)\end{array}$ & $\begin{array}{c}\text { Accuracy }^{3)} \\
(\%)\end{array}$ & $\begin{array}{l}\text { Measured } \\
(\mathrm{ng} / \mu \mathrm{L})\end{array}$ & $\begin{array}{c}\mathrm{RSD} \\
(\%)\end{array}$ & $\begin{array}{c}\text { Accuracy } \\
(\%)\end{array}$ \\
\hline \multirow{3}{*}{ 5-O-methylvisammioside } & 2 & $2.25 \pm 0.02$ & 0.89 & 112.36 & $2.04 \pm 0.01$ & 0.59 & 102.17 \\
\hline & 5 & $5.34 \pm 0.04$ & 0.77 & 106.85 & $5.05 \pm 0.03$ & 0.62 & 101.06 \\
\hline & 10 & $10.27 \pm 0.07$ & 0.72 & 102.66 & $10.08 \pm 0.06$ & 0.60 & 100.76 \\
\hline \multirow{3}{*}{ peucedanol } & 2 & $2.21 \pm 0.02$ & 0.93 & 110.50 & $2.11 \pm 0.02$ & 1.02 & 105.66 \\
\hline & 5 & $5.18 \pm 0.06$ & 1.13 & 103.50 & $5.05 \pm 0.11$ & 2.27 & 101.02 \\
\hline & 10 & $10.12 \pm 0.10$ & 1.00 & 101.19 & $9.84 \pm 0.26$ & 2.66 & 98.43 \\
\hline
\end{tabular}

${ }^{15}$ All values are means $\pm \mathrm{SD},{ }^{2} \mathrm{RSD}$; Relative standard devitation, ${ }^{3)}$ Accuracy $(\%)=($ Measured value/Spiked value $) \times 100$

분석의 정밀성은 $0.59-0.62 \%$, 정확도는 $100.76-102.17 \%$ 의 범위 로 측정되었다. Peucedanol의 일내분석의 정밀성과 정확도는 각 각 0.93-1.13 및 101.19-110.5\% 범위로 측정되었고, 일간분석의 정밀성은 $1.02-2.66 \%$, 및 정확도는 98.43-105.66\%로 측정되었 다. 따라서, 지표성분으로 제안된 두 성분 모두 정밀성의 지표 인 상대 표준편차는 모두 $5 \%$ 이하였으며 정확성의 지표인 회 수율은 $90 \%$ 에서 $110 \%$ 사이의 범위에 근접하게 나와 정밀성 및 정확성이 높은 분석방법임을 확인되었다(Table 2).

$\mathrm{Seo}(2016)$ 등의 선행연구에서 HPLC를 이용한 방풍 및 식방 풍의 분석법 검증이 이뤄진 바 있으나[33], 이번 연구에서는 다 변량 통계 분석을 통하여 방풍, 식방풍을 판별하게 하는 대사 체를 선정하여 지표성분을 제안하였고, 분석법 검증을 진행하였 다. 또한 선행연구가 $\mathrm{HPLC}$ 를 이용한 분석으로 분석시간이 50 분인 것에 비해, 본 연구에서는 30 분 미만의 비교적 빠른 시간 에 방풍 및 식방풍의 지표성분을 분석하였고 분석법 밸리데이 션을 수행하였다. 방풍과 식방풍은 오랫동안 한약재로서 혼용되 어 사용되었으며, 유사한 생리활성에 관한 연구들이 진행되었으 나, 각각 다른 기원식물을 가지며 속과 종이 다른 식물이다. 따 라서, 본 연구의 대사체 프로파일링을 통한 지표성분의 선정 및 $\mathrm{UPLC}$ 를 이용한 분석법이 방풍과 식방풍의 성분 검증을 위한 효과적인 방법이 될 것으로 기대된다.

\section{초 록}

방풍(Saposhnikoviae Radix, SR) 과 식방풍(Peucedani Japonici Radix, PR)은 각각 다른 기원식물을 가지며 속과 종이 다르지 만 한국, 중국, 및 일본에서 대표적인 전통 한약재로 오랫동안 혼용되어 사용되었다. 본 연구에서는 방풍과 식방풍의 판별 마 커를 확인하기 위하여 UPLC-QTOF/MS를 이용한 대사체 프로 파일링 및 다변량 통계분석을 진행하였다. 그 결과, 5-Omethylvisammioside와 peucedanol을 각각 방풍과 식방풍의 지표
성분으로 선정하였으며, UPLC를 이용하여 분석법을 검증하였 다. 제안된 방풍 및 식방풍의 지표성분에 대한 분석법 검증은 방풍과 식방풍의 분류와 품질 평가 및 성분 검증을 위한 효과 적인 방법이 될 것으로 기대된다.

Keywords 다변량분석 방풍 - 밸리데이션 - 식방풍 · 5-O-methylvisammioside $\cdot$ Peucedanol

감사의 글 본 논문은 농촌진흥청 연구사업 (과제번호: PJ01422702)의 지원 에 의해 이루어진 것으로 이에 감사드립니다.

\section{References}

1. Kim MK, Yang DH, Jung M, Jung EH, Eom HY, Suh JH, Min JW, Kim U, Min H, Kim J, Han SB (2011) Simultaneous determination of chromones and coumarins in Radix Saposhnikoviae by high performance liquid chromatography with diode array and tandem mass detectors. J Chromatogr A 1218: 6319-6330

2. Kim SJ, Chin YW, Yoon KD, Ryu MY, Yang MH, Lee JH, Kim J (2008) Chemical Constituents of Saposhnikovia divaricata. Kor J Pharmacogn 39: 357-364

3. Jung JK, Park YK (2012) Effects of Saposhnikoviae Radix on allergic responses in OVA-induced Allergic rhinitis mice. Kor J Herbology 27: 85-91

4. Choi CH, Wang KT, Cho HR, Jeong JG, Jeong HW (2014) Inhibitory Effects of Saposhnikoviae Radix Extracts on the Melanin Production and Elastase Activity in B16F10 cells. Korean J Oriental Physiology \& Pathology 28: 296-302

5. Chun JM, Kim HS, Lee AY, Kim SH, Kim HK (2016) AntiInflammatory and Antiosteoarthritis Effects of Saposhnikovia divaricata ethanol Extract: In Vitro and In Vivo Studies. Evidence-Based Complementary and Alternative Medicine 2016: 1984238

6. Khan S, Kim YS (2013) Molecular mechanism of inflammatory signaling and predominant role of Saposhnikovia divaricata as antiinflammatory potential. Nat Prod Sci 19: 120-126

7. Kang J, Zhou L, Sun JH, Ye M, Han J, Wang BR, Guo DA (2008) Three 
new compounds from the roots of Saposhnikovia divaricata. J Asian Nat Prod Res 10: 971-976

8. Kreiner J, Pang E, Lenon GB, Yang Angela WH (2017) Saposhnikoviae divaricata: a phytochemical, pharmacological, and pharmacokinetic review. Chin J Nat Med 15: 255-264

9. Dai J, Chen X, Cheng W, Liu X, Fan X, Shen Z, Bi Kaishun (2008) A sensitive liquid chromatography-mass spectrometry method for simultaneous determination of two active chromones from Saposhnikovia root in rat plasma and urine. J Chromatogr B 868: 13-19

10. Kim SM, Shin DI, Song HS, Yoon ST (2006) Vegetation Structure of Peucedanum japonicum Thunb. Community in East Seaside of South Korea. Korean J Medicinal Crop Sci 14: 347-353

11. Nam JY, Pyu KS (1975) Pharmacognostical studies on Korea "Bang Poong”. Kor J Pharmacogn 6: 151-159

12. Chun J, Kim J, Kim YS (2018) 3,4-Disenecioylkhellactone from Peucedanum japonicum Thunb. Induces Apoptosis Mediated by Inhibiting STAT3 Signaling in Human Gastric Cancer Cells. Kor J Pharmacogn 49: 225-230

13. Chung SH, Kim KJ, Suh DH, Lee KS, Choi BS (1994) Changes in Growth and Yield of Peucedanum japonicum Thunberg by Planting Time, Mulching, and Planting Density. Korean Journal of Medicinal Crop Science 2: 121-126

14. Jung HK, Sim MO, Jang JH, Kim TM, An BK, Kim MS, Jung WS (2016) Anti-obesity effects of Peucedanum japonicum Thunberg L. on 3T3-L1 cells and high-fat diet-induced obese mice. Korean J Plant Resour 29: 1-10

15. Lim H, Kim I, Jeong Y (2019) Antioxidant Activities of Peucedanum japonicum Thunberg Root Extracts. J Korean Soc Food Sci Nutr 48: 32 39

16. Kim KN, Choi MJ, Lee Y, Cho SH (2013) The Protective and Recovery Effects of Peucedanum Japonicum Thunberg for Vascular Dementia. J of Oriental Neuropsychiatry 24: 123-130

17. Whang WK, Lee SJ, Kim H, Cho H, Lee KS, Kang IH, Han I (2001) Standardization of Peucedani Radix. Kor J Pharmacogn 32: 292-296

18. Hong MJ, Kim J (2017) Determination of the Absolute Configuration of Khellactone Esters from Peucedanum japonicum Roots. J Nat Prod 80: 1354-1360

19. Lee JW, Ji SH, Lee MK, Kim GS, Ahn YS, Ko HJ, Baek NI, Lee DY (2015) Metabolomics Based on UPLC-QTOF/MS Applied for the Discrimination of Cynanchum wilfordii and Cynanchum auriculatum. Metabolomics 5: 4

20. Kim EJ, Kwon J, Park SH, Park C, Seo YB, Shin HK, Kim HK, Lee KS, Choi SY, Ryu DH, Hwang GS (2011) Metabolite Profiling of Angelica gigas from Different Geographical Origins Using ${ }^{1} \mathrm{H}$ NMR and UPLCMS Analyses. J Agric Food Chem 59: 8806-8815

21. Yoon D, Kim S, Lee M, Yoon C, Kim S (2016) 1H-NMR-based metabolomic study on toxicity of methomyl and methidathion in fish.
Journal of Environmental Science and Health, Part B 51:824-831

22. Godzien J, Ciborowski M, Angulo S, Barbas C (2013) From numbers to a biological sense: How the strategy chosen for metabolomics data treatment may affect final results. A practical example based on urine fingerprints obtained by LC-MS. Electrophoresis. 34: 2812-2826

23. Bijisma S, Bobeldijk I, Verheij ER, Ramaker R, Kochhar S, Macdonald IA, Ommen BV, Smilde AK (2006) Large-Scale Human Metabolomics Studies: A Strategy for Data (Pre-) Processing and Validation. Anal. Chem. 78: 567-574

24. Yoon D, Choi BR, Ma S, Lee JW, Jo IH, Lee YS, Kim GS, Kim S, Lee DY (2019) Metabolomics for Age Discrimination of Ginseng Using a Multiplex Approach to HR-MAS NMR Spectroscopy, UPLC-QTOF/ MS, and GC x GC-TOF/MS. Molecules 24: 2381

25. Lee JW, Ji SH, Choi BR, Choi DJ, Lee YG, Kim HG, Kim GS, Kim K, Lee YH, Baek NI, Lee DY (2018) UPLC-QTOF/MS-Based Metabolomics Applied for the Quality Evaluation of Four Processed Panax ginseng Products. Molecules 23: 2062

26. Lin H, Zhu H, Tan J, Wang H, Dong Q, Wu F, Liu Y, Li P, Liu J (2019) Non-Targeted Metabolomic Analysis of Methanolic Extracts of WildSimulated and Field-Grown American Ginseng. Molecules 24: 1053

27. Guo X, Long P, Meng Q, Ho CT, Zhang L (2018) An emerging strategy for evaluating the grades of Keemun black tea by combinatory liquid chromatography-Orbitrap mass spectrometry-based untargeted metabolomics and inhibition effects on $\alpha$-glucosidase and $\alpha$-amylase. Food Chemistry 246: 74-81

28. Kim HS, Choi G, Lee AY (2018) Ultra-performance convergence chromatography method for the determination of four chromones and quality control of Saposhnikovia divaricata (Turcz.) Schischk. J Sep Sci 41: $1682-1690$

29. Chang CZ, Wu SC, Kwan AL, Lin CL (2015) 4-O- $\beta$-D-glucosyl5-O-methylvisam minol, an active ingredient of Saposhnikovia divaricata, attenuates high-mobility group box 1 and subarachnoid hemorrhage-induced vasospasm in a rat model. Behav Brain Funct 11: 28

30. Shin KH, Kang SS, Choi HJ (1992) Analysis of the Coumarin Constituents in Peucedanii Radix. Kor. J. Pharmacogn 23: 20-23

31. Son HK, Kang ST, Jung HO, Lee JJ (1992) Changes in physicochemical properties of Peucedanum japonicum Thunb. after blanching. Korean J Food Preserv 20: 628-635

32. Karakaya S, Koca M, Sytar O, Dursunoglu B, Ozbek H, Duman H, Guvenalp Z, Kilic CS (2019) Antioxidant and anticholinesterase potential of Ferulago cassia with farther bio-guided isolation of active coumarin constituents. South African Journal of Botany 121: 536-542

33. Seo UM, Zhao BT, Kim YH, Kang JS, Son JK, Woo MH (2016) Simultaneous analysis of seven marker compounds from Saposhnikoviae Radix, Glehniae Radix and Peucedani Japonici Radix by HPLC/PDA. Arch Pharm Res 39: 695-704 